\title{
CORRELATION BETWEEN LONG-TERM FERTILIZATION AND SOIL ENZYME ACTIVITY IN THE RHIZOSPHERE OF HALOPHYTES
}

\author{
CHEN, H. W. ${ }^{*}$ - HUANG, L. \\ College of Life Science, Henan Institute of Science and Technology, Xinxiang 453003, China \\ ${ }^{*}$ Corresponding author \\ e-mail: chenhongwei1966@sina.cn
}

(Received $3^{\text {rd }}$ Sep 2019; accepted $12^{\text {th }}$ Feb 2020)

\begin{abstract}
In order to reveal the correlation between long-term different fertilization methods and soil enzyme activity in rhizosphere of halophytes, Salicornia salina was selected as the research object and cultured in root bags in coastal saline soil. The effects of plastic film mulching, non-plastic film mulching and non-fertilization on invertase, catalase and urease activities in rhizosphere soil of Salicornia salsa during its growth period were studied, while the effects of plastic film mulching and non-fertilization on the activities of invertase, catalase and urease in the rhizospheric soil of Salicornia salicornis were also investigated. Bacillus, Bacillus licheniformis, Bacillus amylolytica and compound microbial fertilizers had effects on the activities of three soil enzymes. The results showed that the activities of S-SC, S-CAT and S-UE could be promoted by mulching and that fertilization at any time, and the effect of mulching combined with fertilization was the best. Soil enzyme activity showed the same change pattern during the growth period of Salicornia salina. The highest activity of soil invertase and urease occurred at jointing stage, and the highest activity of soil catalase occurred at maturity stage. Compared to spraying treatment, adding compound microbial fertilizer could increase catalase activity by $6.3 \%$ and $4.0 \%$ at different stages, while adding Bacillus amyloliquefaciens microbial fertilizer, the activity of sucrase and urease increased by $20.7 \%$ and $18.6 \%$, respectively, and $21.8 \%$ and $4.6 \%$, respectively in different periods. In conclusion, the application of plastic film mulching combined with fertilization, inorganic fertilizer and microbial fertilizer can improve soil enzyme activity and soil fertility, and enhance the sustainable productivity of soil.
\end{abstract}

Keywords: appropriate temperatures, phosphorus, potassium, microbial fertilizer

\section{Introduction}

Soil is a living ecosystem, containing various soil enzymes. They play an important role in the process of soil material circulation, energy and nutrient transformation (Tang et al., 2016). The activity of soil enzymes is one of the biological indicators to characterize soil biological activity, soil fertility level and soil quality. Nature and environmental conditions are closely related, and are regarded as sensitive indicators of soil ecosystem change (Cunha et al., 2017). Soil enzymes are proteins that catalyze soil biochemical reactions, mainly from soil microorganisms and plant roots, and also from soil animals and plant residues (Cheng et al., 2016), which are one of the most active organic components in soil components. Plant rhizosphere is the place where plant roots grow and develop, absorb nutrients and metabolize. It is also an important interface between plant and soil environment (Nawaz et al., 2016). The effect of plant living roots on soil enzyme activities is reflected in two aspects. On the one hand, plant roots can secrete extracellular enzymes; on the other hand, they may also be root thorns. It stimulates the activity of soil microorganisms. It is more sensitive to the soil environment and more responsive to the soil environment. Rhizosphere is also the most active micro domain of soil chemical and biological properties, and its importance has been widely recognized. Soil enzyme activity, 
as a quick-acting index to measure the rhizosphere micro-ecological environment, has been widely used in the study of soil ecological environment. Therefore, the study of soil enzyme activity is of great significance to the formation, evolution, and improvement of soil fertility and the material cycle process of soil ecosystem (Fan et al., 2016).

Soil invertase (S-SC), catalase (S-CAT) and soil urease (S-UE) activities play an important role in evaluating soil fertility. Among them, S-SC activity reflects the intensity of soil respiration and carbon transformation (Van et al., 2017), and has been widely used to characterize the intensity and direction of soil carbon cycle and biochemical activity. SCAT is an indicator of aerobic microorganisms. It can effectively promote the decomposition of harmful substance hydrogen peroxide, which is related to the redox capacity of soil and the transformation rate of soil organic matter (Chen et al., 2018). The activity of S-UE represents the abundance of soil nitrogen and is closely related to the transformation of nitrogen in soil. Therefore, the activity of S-UE is commonly used to characterize soil nitrogen status (Liu et al., 2016). At present, there are a lot of reports about the effect of organic fertilizer on soil enzyme activity. Fertilizer application is the way to apply fertilizer to soil. The basic requirements of scientific fertilization methods are as follows: to apply fertilizer to the soil layer which is easy to absorb by the root system of the crop as far as possible, to improve the utilization rate of chemical fertilizer; to select the appropriate location and to reduce fertilizer fixation, volatilization and leaching. Fertilization methods vary with different crops, fertilization loss and fertilizer properties. The most commonly used methods are artificial spraying, acupoint application, rotation, radial fertilization and external fertilization. According to the planting mode of Salicornia salsa, artificial spraying and hole fertilization (Ma et al., 2016) were used in the fertilization process, and after fertilization, sowing was conducted. Microbial fertilizer is applied in the same hole as seed fertilizer. The mixed strains were Bacillus subtilis, Bacillus licheniformis and Bacillus amyloliquefaciens.

Halophyte is a kind of natural plant flora (Poeplau et al., 2016) which grows on saline soil with certain salt resistance. Phytoremediation on saline-alkali soil is a feasible method to solve the problem of saline-alkali land utilization. Therefore, the research on the phytoremediation of saline-alkali soil by plant rhizosphere has received extensive attention. The strong salt and barren tolerance of coastal halophytes may also be related to their rhizosphere soil enzymes. The rhizosphere soil enzymes of halophytes may be one of the most direct characteristics of coastal halophytes to rapidly absorb, utilize soil nutrients and adapt to saline environment (Zhao et al., 2016). The research of plant rhizosphere is very limited, especially the soil enzyme activities of these plants are seldom concerned. Studying the soil enzyme activities of coastal halophytes will help to protect the resources of Halophytes in these areas, and provide a theoretical basis for the restoration and utilization of these plants in coastal saline soil. Based on this, the correlation between long-term different fertilization methods and soil enzyme activities in rhizosphere of halophytes was studied. The activities and dynamic changes of S-SC, SCAT and S-UE in rhizosphere of five fertilization treatments under artificial spraying and hole application during the growth period of halophyte Salicornia salina were mainly studied in order to clarify different microorganisms. The intrinsic relationship between fertilizer and soil enzyme activity provides theoretical basis for rational fertilization, soil improvement and seeking the best growth environment for stable and high yield of halophytes. In order to reveal the correlation between long-term different fertilization methods and soil enzyme activity in rhizosphere of halophytes, Salicornia salina was selected as the research object and cultured in root bags in coastal saline soil. 


\section{Materials and Methods}

\section{Halophytes and soils}

Generally speaking, the basic conditions for plant growth are: moderate sunshine, air and water. The five essential elements of plant life are: sunlight, temperature, water, air and nourishment, which are the lifeline of plants. Temperature has a great influence on the growth and development of plants. Plants need different and appropriate temperatures in different growth periods and development stages; water is an important part of plants; oxygen, nitrogen and carbon dioxide in the air have a great impact on plant life; plants need a lot of nutrients, including carbon, hydrogen, oxygen, nitrogen, phosphorus, potassium, calcium, sulfur, magnesium, iron and other 10 kinds of elements. Air affects the lives of animals and plants. The photosynthesis of plants needs carbon monoxide, and the respiration of animals needs oxygen. Only under light conditions can plants carry out photosynthesis, produce organics and store energy every day. Light plays a decisive role in plant physiology and distribution. Some plants can grow well only under strong light, such as wheat, corn, etc.

Salicornia salina, a typical halophyte in northern coastal areas of China, was selected to adapt to the coastal saline soil environment. Salicornia salina is a salt-accumulating halophyte (Xu et al., 2017). Seeds of the tested plants were collected in the coastal area of Dagang, Tianjin, in October 2016. The coastal saline soil with natural distribution of halophytes was selected for the tested soil, and the basic properties of the soil were shown in Table 1.

Table 1. Main properties of soils used

\begin{tabular}{c|c}
\hline Soil properties & Littoral rock and soil \\
\hline $\mathrm{PH}$ value & 8.52 \\
$\mathrm{w}($ Total salt $)\left(\mathrm{g} \cdot \mathrm{kg}^{-1}\right)$ & 12.72 \\
$\mathrm{w}\left(\mathrm{CO}_{3}{ }^{2-}\right)\left(\mathrm{g} \cdot \mathrm{kg}^{-1}\right)$ & 0.08 \\
$\mathrm{w}\left(\mathrm{HCO}^{3-}\right)\left(\mathrm{g} \cdot \mathrm{kg}^{-1}\right)$ & 0.17 \\
$\mathrm{w}\left(\mathrm{CI}^{-}\right)\left(\mathrm{g} \cdot \mathrm{kg}^{-1}\right)$ & 7.15 \\
$\mathrm{w}\left(\mathrm{SO}_{4}{ }^{2-}\right)\left(\mathrm{g} \cdot \mathrm{kg}^{-1}\right)$ & 0.75 \\
$\mathrm{w}\left(\mathrm{Na}^{+}\right)\left(\mathrm{g} \cdot \mathrm{kg}^{-1}\right)$ & 2.63 \\
$\mathrm{w}\left(\mathrm{K}^{+}\right)\left(\mathrm{g} \cdot \mathrm{kg}^{-1}\right)$ & 1.50 \\
$\mathrm{w}\left(\mathrm{Ca}^{2+}\right)\left(\mathrm{g} \cdot \mathrm{kg}^{-1}\right)$ & 1.49 \\
$\mathrm{w}\left(\mathrm{Mg}^{2+}\right)\left(\mathrm{g} \cdot \mathrm{kg}^{-1}\right)$ & 0.20 \\
$\mathrm{w}($ Quick-actingN $)\left(\mathrm{mg} \cdot \mathrm{kg}^{-1}\right)$ & 30.18 \\
$\mathrm{w}($ Quick-actingP $)\left(\mathrm{mg} \cdot \mathrm{kg}^{-1}\right)$ & 12.63 \\
$\mathrm{w}($ Quick-actingK $)\left(\mathrm{mg} \cdot \mathrm{kg}^{-1}\right)$ & 384 \\
\hline
\end{tabular}

\section{Root bag culture and sample collection of plants}

The experiment began on May 9, 2017. Firstly, the soil was collected, dried, crushed and fully blended, grinded over $0.2 \mathrm{~mm}$ sieve, and then added distilled water to the soil water content of $140 \mathrm{~g} \cdot \mathrm{kg}^{-1}$ for reserve. The potted root bag method was used to simulate the experiment ( $\mathrm{Gu}$ et al., 2016). All the experiments were carried out in greenhouse. The nylon mesh yarn with $30 \mu \mathrm{m}$ aperture was sealed with a plastic sealing machine to form a root bag with a diameter of $3 \mathrm{~cm}$ and a height of $15 \mathrm{~cm}$. The root bags of Salicornia salicornis could not grow out. Each root bag was filled with $240 \mathrm{~g}$ of prepared soil (Chen et al., 2017). The same soil was also put into a basin with a height 
of $40 \mathrm{~cm}$ and a diameter of $30 \mathrm{~cm}$, and then one of the prepared root bags was buried in the center of the basin. Fifteen dew-white seeds of Salicornia salsa were planted in each root bag, and six seedlings were retained in each root bag after emergence. Water every 15 days during the growth period, and pour the same amount of distilled water $3 \mathrm{~L}$ for each treatment, and do not do any other treatment. After 100 days of plant growth, 12 pots with similar seedling emergence and growth were selected for sampling, i.e. 12 replicates. When all the roots of Salicornia salsa were observed to be fully filled with root bags, the soil below $2 \mathrm{~cm}$ in the root bags was taken as rhizosphere soil, and the soil samples were dried in shade to be tested.

\section{Fertilizer for test and test design}

There are three kinds of fertilization methods: film-covered fertilization (CF), film-covered non-fertilization (C), non-film-covered fertilization (F) (Gschwendtner et al., 2016), and non-mulching and non-fertilization (CK) as control. Samples were taken for 15,30 and 45 days after treatment. There are 10 treatments in the fertilization process, and the different treatment schemes are shown in Table 2.

Table 2. Test design scheme

\begin{tabular}{|c|c|c|c|}
\hline $\begin{array}{c}\text { Serial } \\
\text { number }\end{array}$ & Code & Handle & $\begin{array}{c}\text { Consumption/ } \\
\mathrm{g}\end{array}$ \\
\hline 1 & $\mathrm{SCK}$ & Manual application of chemical fertilizer & 1.5 \\
\hline 2 & TCK & Point application of chemical fertilizer & 1.5 \\
\hline 3 & SKC & $\begin{array}{l}\text { Manual Spraying of Chemical Fertilizer + Microbial Fertilizer } \\
\text { (Bacillus subtilis) }\end{array}$ & $1.5+3.0$ \\
\hline 4 & TKC & $\begin{array}{l}\text { Point Application of Chemical Fertilizer }+ \text { Microbial Fertilizer } \\
\text { (Bacillus subtilis) }\end{array}$ & $1.5+3.0$ \\
\hline 5 & SDY & $\begin{array}{c}\text { Manual fertilization }+ \text { microbial fertilizer (Bacillus } \\
\text { licheniformis) }\end{array}$ & $1.5+3.0$ \\
\hline 6 & TDY & $\begin{array}{l}\text { Point Application of Chemical Fertilizer }+ \text { Microbial Fertilizer } \\
\text { (Bacillus licheniformis) }\end{array}$ & $1.5+3.0$ \\
\hline 7 & SJDF & $\begin{array}{c}\text { Manual fertilization }+ \text { microbial fertilizer (Bacillus } \\
\text { amylolytica) }\end{array}$ & $1.5+3.0$ \\
\hline 8 & TJDF & $\begin{array}{c}\text { Point Application of Chemical Fertilizer + Microbial Fertilizer } \\
\text { (Bacillus amyloliquefaciens) }\end{array}$ & $1.5+3.0$ \\
\hline 9 & $\mathrm{SFH}$ & $\begin{array}{c}\text { Manual Spraying of Chemical Fertilizer + Microbial Fertilizer } \\
\text { (Compound Bacteria) }\end{array}$ & $1.5+3.0$ \\
\hline 10 & TFH & $\begin{array}{c}\text { Point Application of Chemical Fertilizer + Microbial Fertilizer } \\
\text { (Compound Bacteria) }\end{array}$ & $1.5+3.0$ \\
\hline
\end{tabular}

According to the characteristics of rapid cooling and unstable temperature in saline soil area in the morning and evening, fertilization treatment was carried out in June 20, July 1 and July 10, respectively. The test chemical fertilizer was Stanley slow-release mixed fertilizer ( $\left.\mathrm{N}: \mathrm{P}_{2} \mathrm{O}_{5}: \mathrm{K}_{2} \mathrm{O}=26: 12: 10\right)$ (Liu et al., 2016). The microbial fertilizer was organic fertilizer plus $10 \%$ bacteria (bacteria $2 \times 10^{10} \mathrm{cfu} / \mathrm{g}$ ) and organic matter content was $40.857 \%$ ( $\mathrm{Li}$ et al., 2017). The tested strains were Bacillus subtilis, Bacillus licheniformis and Bacillus amyloliquefaciens (Gong et al., 2017), which were preserved by the Biochemical Laboratory of Institute of Applied Chemistry, Shanxi University. 


\section{Artificial spraying}

Artificial spraying is the way of evenly spreading fertilizer on the field (Duan and Liu, 2019), which belongs to topsoil fertilization and mainly meets the needs of shallow root distribution at seedling stage. This method is commonly used in the application of base fertilizer to uncultivated crops or in the topdressing of densely planted grain crops (Wang et al., 2018). Artificial spraying combined with soil tillage measures can increase the uniformity of soil and fertilizer mixing, which is conducive to the extension of crop roots and early absorption.

\section{Point application}

Point application can be made by opening hole fertilizer in the designated planting position or termination of the crop, or in the seedling stage, per plant or between two sides of the plant during the crop growth period (Zhou and Lin, 2016). Point fertilizer is usually $5-10 \mathrm{~cm}$ deep and covered with soil after application. Point application is a more centralized method of chemical fertilizer application, avoiding damage to the root system. Generally, less chemical fertilizer is applied, and the appropriate position and depth are maintained with the root system of crops. After fertilization, irrigation is combined before covering soil, and the effect of chemical fertilizer application is better.

\section{Determination of nutrients and active enzymes in soil}

Soil samples are used for the determination of various indicators after indoor shade drying. Soil nutrient determination methods: Kjeldahl method for total nitrogen, $\mathrm{HCl}-\mathrm{HF}$ method for digestion of total phosphorus, anti-colorimetric method for molybdenum and antimony, alkali hydrolysis diffusion method for available nitrogen and Bray1 method for available phosphorus.

The activity of S-SC (soil sucrase) was determined by the colorimetric method using 3,5-Dinitrosalicylic acid as the chromogenic agent (Song et al., 2018). S-SC can enzymatically hydrolyze sucrose to produce glucose and fructose. The hydrolyzed sucrose can form colored compounds with 3,5-Dinitrosalicylic acid. The content of glucose can be determined by colorimetry. The activity of S-SC was expressed by the quality of soil glucose (mg) $1 \mathrm{~g}$ after 24 hours (Hicks et al., 2017).

The activity of S-CAT was determined by titration with $0.1 \mathrm{~mol} \cdot \mathrm{L}^{-1} \mathrm{KMnO} 4$ using hydrogen peroxide as matrix, and the activity of S-CAT was expressed by the amount of $0.1 \mathrm{~mol} \cdot \mathrm{L}^{-1} \mathrm{KMnO} 4$ consumed by $1 \mathrm{~g}$ of dry soil after 20 minutes of incubation.

The activity of S-UE (urease) was determined by urea residue method. S-UE can hydrolyze urea into ammonia, water and carbon dioxide. After incubating fresh soil and urea at $37^{\circ} \mathrm{C}$ for 5 hours, the urea residue was determined and the activity of S-UE was estimated. The activity of S-UE was expressed by the mass (mg) of urea nitrogen reduction per unit time.

\section{Data processing}

Microsoft Excel 2016 and SPSS 22.0 were used to analyze the test data. The determination of s-ue (urease) activity by urea residue method is improved on the basis of research method: take $1 \mathrm{~g}$ soil (rhizosphere soil stored at $-20^{\circ} \mathrm{C}$ ) and add $9 \mathrm{ml}$ sterile water, mix it with vortex, take $200 \mu \mathrm{l}$ soil suspension respectively and add it into $50 \mathrm{ml}$ sterilized medium (Ca-P, Fe-P and Al-P liquid medium), culture it in $160 \mathrm{r} \mathrm{min}^{-1}$ shaking bed at $30^{\circ} \mathrm{C}$ for 9 days, and take $5 \mathrm{ml}$ soil suspension every 1 day. After 
centrifugation at $4000 \mathrm{r} \min ^{-1}$ and $4^{\circ} \mathrm{C}$ for $10 \mathrm{~min}$, the supernatant was taken to determine the effective phosphorus content and $\mathrm{pH}$. The treatment was repeated 3 times.

\section{Results}

\section{Effects of different fertilization periods and modes on soil enzyme activities in the rhizosphere of Salicornia Salsa}

In order to verify the effect and feasibility of the method in this paper, an experiment is set up for verification. The soil culture dish diagram of the experimental plant is shown in Figure 1.

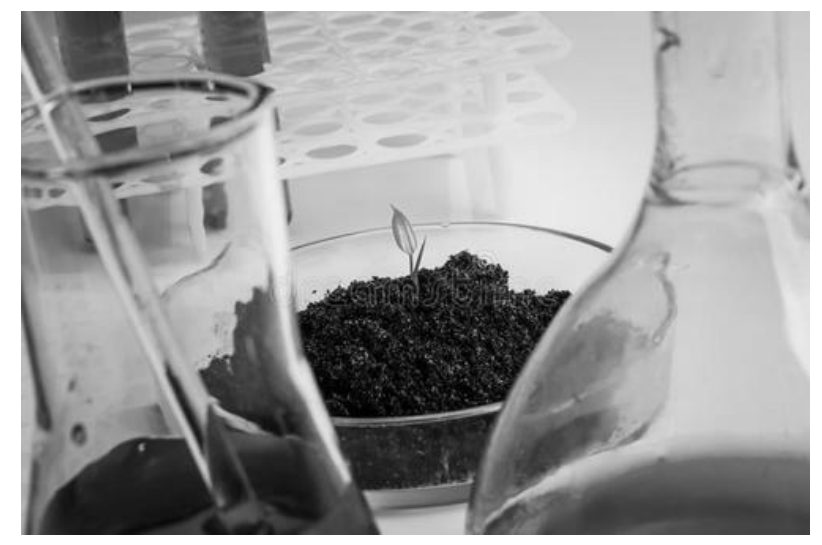

Figure 1. Dish chart of experimental plant soil

Effects of different fertilization periods and modes on S-SC activity of Salicornia salsa rhizosphere

Table 3 describes the effects of different fertilization stages and modes on S-SC activity in the rhizosphere of Salicornia salina.

Table 3 showed that both fertilization and mulching methods were beneficial to the improvement of S-SC activity in Salicornia salina rhizosphere soil. The effect of film mulching combined with fertilization was the best, and the S-SC activity was significantly higher than that of non-film mulching and non-fertilization, showing significant difference. Among them, S-SC activity was the highest on June 20 when the fertilizer was applied with plastic film for 15 days. The S-SC activity of mulching treatment and fertilization treatment also increased, but the effect of the two treatments was different. The S-SC activity of mulching treatment was the highest at 15 days of sampling on July 1 , and the S-SC activity of fertilization treatment was the highest at 45 days of sampling on July 1. Soil S-SC activity was also affected by different fertilization stages, which showed that the S-SC activity was the highest in the treatment on July 1. The S-SC activity of each treatment was higher in the 15-day sampling on June 20. The S-SC activity of each treatment was higher in the 45-day sampling on July 1. The S-SC activity of each treatment was higher in the 45-day sampling on July 10. The S-SC active phase of each treatment was the highest in the 45-day sampling on July 10. 
Table 3. Effects of different fertilization methods on soil S-SC activity under different fertilization time

\begin{tabular}{c|c|c|c|c}
\hline \multirow{2}{*}{$\begin{array}{c}\text { Fertilization } \\
\text { time }\end{array}$} & Fertilization & \multicolumn{2}{|c}{ S-SC activity in rhizosphere soil (U/g) } \\
\cline { 3 - 5 } methods & $\mathbf{1 5 d}$ & $\mathbf{3 0 d}$ & $\mathbf{4 5 d}$ \\
\hline \multirow{3}{*}{$20 \mathrm{June}$} & $\mathrm{CF}$ & $4.70 \pm 0.27 \mathrm{a}$ & $2.02 \pm 0.30 \mathrm{~b}$ & $2.74 \pm 0.02 \mathrm{ab}$ \\
& $\mathrm{C}$ & $2.50 \pm 0.06 \mathrm{bcde}$ & $1.85 \pm 0.49 \mathrm{bc}$ & $1.58 \pm 0.12 \mathrm{c}$ \\
& $\mathrm{F}$ & $1.51 \pm 0.27 \mathrm{de}$ & $1.92 \pm 0.18 \mathrm{bc}$ & $1.87 \pm 0.08 \mathrm{bc}$ \\
& $\mathrm{CK}$ & $1.12 \pm 0.14 \mathrm{e}$ & $1.05 \pm 0.02 \mathrm{de}$ & $1.13 \pm 0.10 \mathrm{c}$ \\
& $\mathrm{CF}$ & $3.35 \pm 1.57 \mathrm{~b}$ & $3.64 \pm 0.27 \mathrm{a}$ & $3.73 \pm 1.05 \mathrm{a}$ \\
& $\mathrm{C}$ & $3.22 \pm 2.02 \mathrm{bc}$ & $1.81 \pm 0.32 \mathrm{bc}$ & $2.70 \pm 0.85 \mathrm{ab}$ \\
& $\mathrm{F}$ & $2.88 \pm 0.02 \mathrm{bcd}$ & $2.18 \pm 0.08 \mathrm{~b}$ & $3.61 \pm 1.30 \mathrm{a}$ \\
& $\mathrm{CK}$ & $1.64 \pm 0.01 \mathrm{de}$ & $1.46 \pm 0.27 \mathrm{~cd}$ & $1.40 \pm 0.22 \mathrm{c}$ \\
& $\mathrm{CF}$ & $1.90 \pm 0.32 \mathrm{cde}$ & $3.20 \pm 0.35 \mathrm{a}$ & $3.37 \pm 0.41 \mathrm{a}$ \\
& $\mathrm{C}$ & $1.36 \pm 0.09 \mathrm{e}$ & $1.86 \pm 0.55 \mathrm{bc}$ & $1.43 \pm 0.26 \mathrm{c}$ \\
& $\mathrm{F}$ & $1.33 \pm 0.03 \mathrm{e}$ & $1.01 \pm 0.02 \mathrm{de}$ & $1.78 \pm 0.16 \mathrm{bc}$ \\
& $\mathrm{CK}$ & $1.30 \pm 0.10 \mathrm{e}$ & $0.92 \pm 0.09 \mathrm{e}$ & $0.88 \pm 0.12 \mathrm{c}$ \\
\hline
\end{tabular}

Different lower-case letters in the same column in the table show significant differences at the level of 0.05 , the same below

Effects of different fertilization periods and manners on $S$-CAT activity in rhizosphere of Salicornia salina

Table 4 describes the effects of different fertilization stages and modes on S-CAT activity in the rhizosphere of Salicornia salina.

Table 4. Effects of different fertilization periods and manners on S-CAT activity in rhizosphere of Salicornia salina

\begin{tabular}{c|c|c|c|c}
\hline \multirow{2}{*}{$\begin{array}{c}\text { Fertilization } \\
\text { time }\end{array}$} & Fertilization & \multicolumn{3}{|c}{ S-CAT activity in rhizosphere soil (U/mL) } \\
\cline { 3 - 5 } & methods & 15d & 30d & 45d \\
\hline \multirow{4}{*}{20 June } & CF & $14.77 \pm 0.15 \mathrm{a}$ & $10.13 \pm 0.25 \mathrm{~b}$ & $11.37 \pm 0.06 \mathrm{a}$ \\
& $\mathrm{C}$ & $11.77 \pm 0.15 \mathrm{~b}$ & $8.13 \pm 0.15 \mathrm{~d}$ & $10.87 \pm 0.15 \mathrm{~b}$ \\
& $\mathrm{~F}$ & $7.40 \pm 0.20 \mathrm{e}$ & $9.30 \pm 0.36 \mathrm{c}$ & $10.30 \pm 0.10 \mathrm{c}$ \\
& $\mathrm{CK}$ & $7.23 \pm 0.06 \mathrm{ef}$ & $7.76 \pm 0.60 \mathrm{de}$ & $5.20 \pm 0.66 \mathrm{~g}$ \\
& $\mathrm{CF}$ & $12.37 \pm 00.31 \mathrm{~b}$ & $10.37 \pm 0.42 \mathrm{~b}$ & $8.50 \pm 0.40 \mathrm{~d}$ \\
& $\mathrm{C}$ & $12.33 \pm 0.06 \mathrm{~b}$ & $9.83 \pm 0.50 \mathrm{bc}$ & $6.87 \pm 0.25 \mathrm{e}$ \\
& $\mathrm{F}$ & $10.40 \pm 0.50 \mathrm{~cd}$ & $9.87 \pm 0.06 \mathrm{bc}$ & $6.70 \pm 0.20 \mathrm{e}$ \\
& $\mathrm{CK}$ & $5.23 \pm 0.65 \mathrm{~g}$ & $7.67 \pm 0.25 \mathrm{de}$ & $4.40 \pm 0.10 \mathrm{~h}$ \\
& $\mathrm{CF}$ & $10.97 \pm 0.60 \mathrm{c}$ & $14.13 \pm 0.25 \mathrm{a}$ & $8.47 \pm 0.23 \mathrm{~d}$ \\
& $\mathrm{C}$ & $9.83 \pm 0.06 \mathrm{~d}$ & $7.33 \pm 0.32 \mathrm{e}$ & $6.63 \pm 0.40 \mathrm{e}$ \\
& $\mathrm{F}$ & $7.57 \pm 0.15 \mathrm{e}$ & $7.57 \pm 0.12 \mathrm{de}$ & $5.70 \pm 0.20 \mathrm{f}$ \\
& $\mathrm{CK}$ & $6.77 \pm 0.42 \mathrm{f}$ & $5.30 \pm 0.10 \mathrm{f}$ & $4.00 \pm 0.20 \mathrm{~h}$ \\
\hline
\end{tabular}

Table 4 shows that both fertilization and mulching methods are beneficial to the improvement of S-CAT activity in Salicornia salina rhizosphere soil. The effect of combined application of film mulching and fertilizer was the best, and the activity of S-CAT was significantly higher than that of non-film mulching and non-fertilization, showing a significant difference. The S-CAT activity was the highest on June 20 when the treatment of plastic film mulching fertilization was sampled for 15 days. The S-CAT activity of plastic film mulching treatment and fertilization treatment also increased, but 
the effect of the two treatments was different. The S-CAT activity of the two treatments was the highest when they were sampled for 15 days on July 1. Different fertilization time also affected the activity of S-CAT, which was the highest in the treatment on July 1 , and it was found that the activity of S-CAT was higher in the treatment on the 15th day of sampling.

Effects of different fertilization periods and manners on S-UE activity in rhizosphere of Salicornia salsa

Table 5 describes the effects of different fertilization periods and modes on S-UE activity in the rhizosphere of Salicornia salina.

Table 5. Effects of different fertilization periods and manners on S-UE activity in rhizosphere of Salicornia salsa

\begin{tabular}{c|c|c|c|c}
\hline \multirow{2}{*}{$\begin{array}{c}\text { Fertilization } \\
\text { time }\end{array}$} & Fertilization & \multicolumn{3}{|c}{ S-UE activity in rhizosphere soil (U/g) } \\
\cline { 3 - 5 } & methods & $\mathbf{1 5 d}$ & $\mathbf{3 0 d}$ & $\mathbf{4 5 d}$ \\
\hline \multirow{4}{*}{$20 \mathrm{June}$} & $\mathrm{CF}$ & $48.94 \pm 3.28 \mathrm{~b}$ & $37.71 \pm 0.85 \mathrm{a}$ & $2293 \pm 1.55 \mathrm{cde}$ \\
& $\mathrm{C}$ & $30.29 \pm 1.92 \mathrm{~d}$ & $24.08 \pm 1.24 \mathrm{~b}$ & $21.69 \pm 3.19 \mathrm{de} 3$ \\
& $\mathrm{~F}$ & $34.59 \pm 3.39 \mathrm{c}$ & $18.06 \pm 2.89 \mathrm{bc}$ & $17.75 \pm 0.11 \mathrm{fg}$ \\
& $\mathrm{CK}$ & $20.97 \pm 1.75 \mathrm{ef}$ & $9.15 \pm 1.34 \mathrm{~d}$ & $12.91 \pm 0.87 \mathrm{~h}$ \\
& $\mathrm{CF}$ & $75.77 \pm 0.40 \mathrm{a}$ & $38.32 \pm 10.29 \mathrm{a}$ & $33.34 \pm 0.46 \mathrm{a}$ \\
& $\mathrm{C}$ & $22.95 \pm 1.70 \mathrm{e}$ & $32.16 \pm 1.98 \mathrm{a}$ & $30.01 \pm 3.31 \mathrm{~b}$ \\
& $\mathrm{~F}$ & $34.76 \pm 0.06 \mathrm{c}$ & $33.34 \pm 2.94 \mathrm{a}$ & $24.81 \pm 0.06 \mathrm{c}$ \\
& $\mathrm{CK}$ & $22.10 \pm 1.08 \mathrm{ef}$ & $20.35 \pm 5.65 \mathrm{bc}$ & $16.56 \pm 0.12 \mathrm{~g}$ \\
& $\mathrm{CF}$ & $30.86 \pm 3.39 \mathrm{~cd}$ & $33.91 \pm 2.26 \mathrm{a}$ & $23.10 \pm 0.69 \mathrm{~cd}$ \\
& $\mathrm{C}$ & $24.47 \pm 4.02 \mathrm{e}$ & $24.70 \pm 1.19 \mathrm{~b}$ & $20.22 \pm 1.16 \mathrm{ef}$ \\
& $\mathrm{F}$ & $28.94 \pm 1.47 \mathrm{~d}$ & $20.63 \pm 1.53 \mathrm{bc}$ & $16.65 \pm 1.21 \mathrm{~g}$ \\
& $\mathrm{CK}$ & $18.20 \pm 2.60 \mathrm{f}$ & $16.23 \pm 1.76 \mathrm{c}$ & $11.80 \pm 1.26 \mathrm{~h}$ \\
\hline
\end{tabular}

Table 5 shows that both fertilization and film mulching are beneficial to the improvement of S-UE activity in Salicornia rhizosphere soil. The effect of film mulching combined with fertilization was the best, and the S-UE activity was significantly higher than that of non-film mulching and non-fertilization, showing significant difference. The S-UE activity was the highest on July 1 st when the film mulching treatment was taken for 15 days. The S-UE activity of mulching treatment and fertilization treatment also increased, but the effect of the two treatments was different. The S-UE activity of mulching treatment was the highest at 30 days of sampling on July 1, and the S-UE activity of fertilization treatment was the highest at 15 days of sampling on July 1 . The activity of S-UE was also affected by different fertilization periods. The highest activity of S-UE was observed on July 1. At the same time, it was found that the activity of S-CAT was higher in different fertilization methods at different time.

\section{Effects of point fertilization on soil enzyme activity}

\section{Effect of point fertilization on S-SC activity}

Figure 2 depicts the effect of hole fertilization on S-SC activity under plastic film mulching. Different lower-case letters in the picture showed significant difference $(\mathrm{P}<0.05)$, and the following is no longer repeated. 


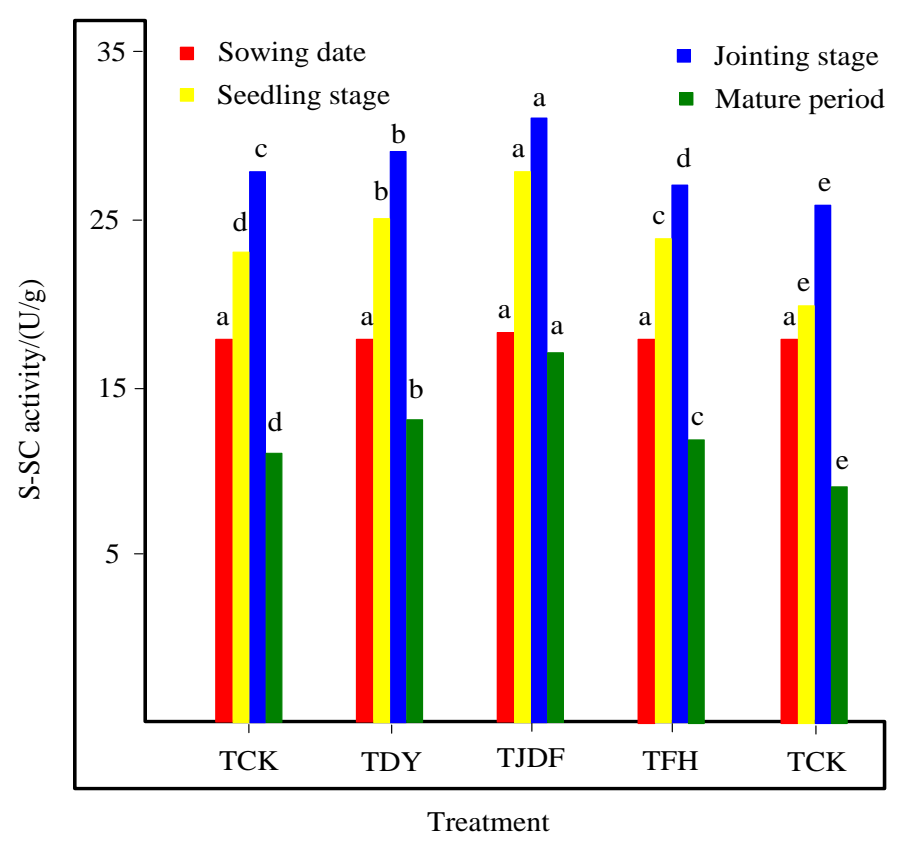

Figure 2. Effects of point-based fertilization on S-SC activity

Figure 2 shows that the S-SC activity of Salicornia salicornis showed the same change rule during its growth period, and reached the maximum at jointing stage, then decreased gradually. The activity of S-SC was higher than that of control, and TJDF had the greatest influence on S-SC activity. Compared with the single application of chemical fertilizer (TCK), the enzymatic activities of TJDF treatment increased by $41.9 \%, 20.7 \%$ and $68.0 \%$ at seedling stage, jointing stage and maturity stage, $15.1 \%$, $8.7 \%$ and $16.6 \%$ in TKC treatment, $23.7 \%, 12.8 \%$ and $33.1 \%$ in TDY treatment, $17.3 \%$, $4.1 \%$ and $23.2 \%$ in TFH treatment, respectively. It can be seen that the increase of S-SC activity can be promoted by applying microbial fertilizer. Among them, microbial fertilizer combined with chemical fertilizer (Bacillus amylolytica) has the most obvious effect, followed by microbial fertilizer combined with chemical fertilizer (Bacillus licheniformis).

\section{Effects of point-based fertilization on S-CAT activity}

Figure 3 depicts the effect of hole fertilization on S-CAT activity under plastic film mulching.

Figure 3 shows that the activity of S-CAT increases gradually during the growth period of Salicornia salsa. The highest value occurs in the mature stage. The fertilization treatments mainly based on hole application show that TFH treatment has the most significant effect on the activity of S-CAT. Compared with TCK, the activity of S-CAT increased by $7.6 \%, 9.0 \%$ and $6.3 \%$ at seedling stage, jointing stage and mature stage, respectively. Therefore, the application of microbial fertilizer can improve the activity of S-CAT, and the effect of microbial fertilizer combined with chemical fertilizer (compound bacteria) is the most obvious. Other fertilization treatments inhibited S-CAT activity. 


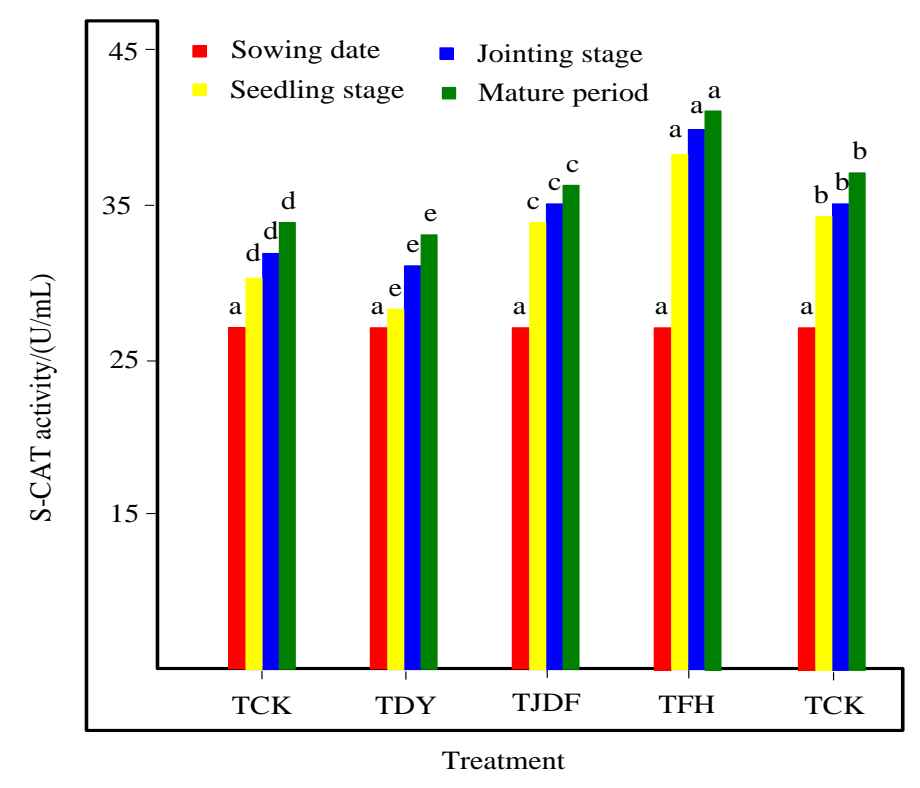

Figure 3. Effects of point-based fertilization on S-CAT activity

\section{Effects of point fertilization on $S$-UE activity}

Figure 4 depicts the effect of hole fertilization on S-UE activity under plastic film mulching.

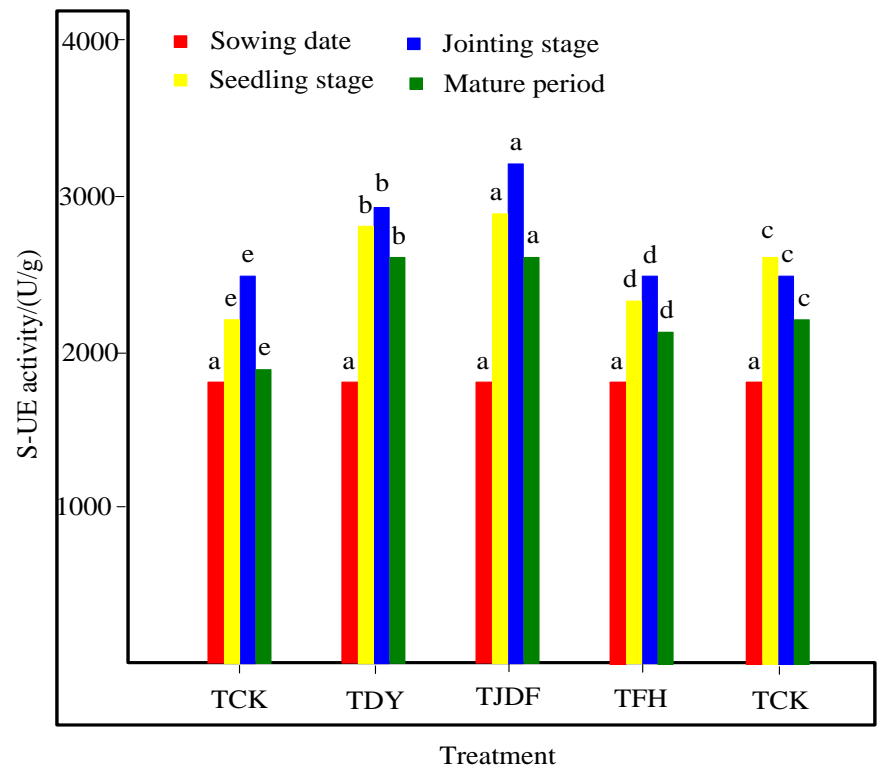

Figure 4. Effects of point-based fertilization on S-UE activity

Figure 4 shows that the activity of S-UE increases first and then decreases during the growth period of Salicornia salina, and reaches its peak at jointing stage. Among them, TJDF treatment had the greatest effect on S-UE activity, which increased by $15.8 \%$, $30.4 \%$ and $21.8 \%$ at seedling stage, jointing stage and maturity stage, compared with 
TCK alone, while TDY treatment increased by $12.7 \%, 19.7 \%$ and $19.9 \%$ respectively. Therefore, the increase of S-UE activity can be promoted by applying microbial fertilizer, the most significant effect is the combination of chemical fertilizer and microbial fertilizer (Bacillus amyloliquefaciens), followed by microbial fertilizer (Bacillus licheniformis).

\section{Effects of fertilizer application on soil enzyme activities}

Effects of spraying-based fertilization on S-SC activity

Figure 5 depicts the effect of spraying fertilization on S-SC activity under mulched fertilization.

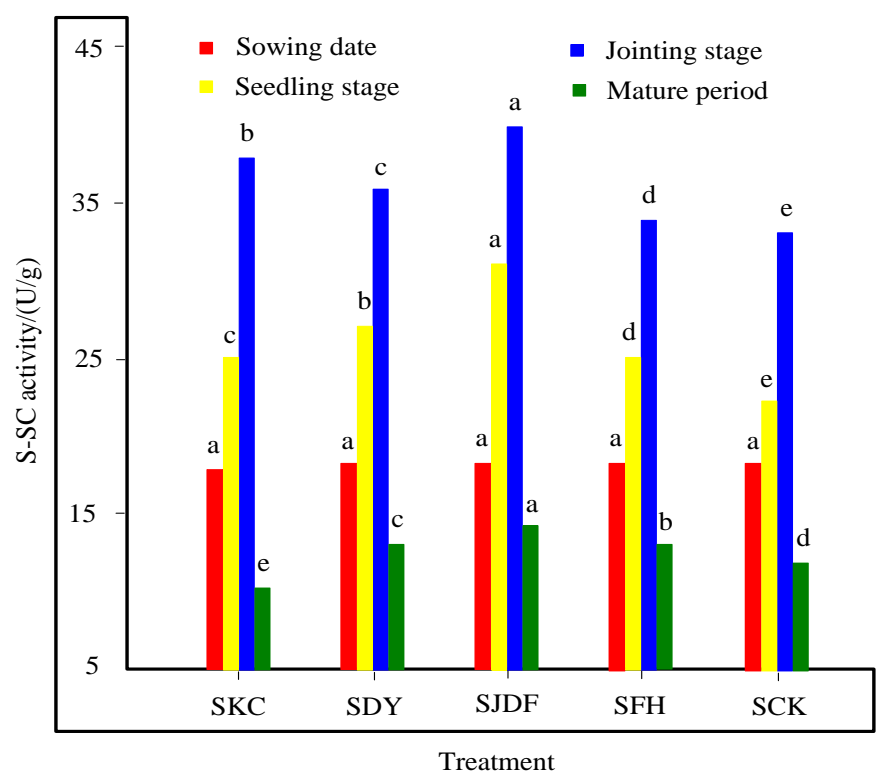

Figure 5. Effects of spraying-based fertilization on S-SC enzyme activity

From Figure 5, we can see that S-SC activity reached the highest level at jointing stage of Salicornia salsa under spraying mode, and then decreased gradually. Among them, SJDF treatment had the highest enzymatic activity, which increased by $37.4 \%$, $18.6 \%$ and $22.9 \%$ at seedling stage, jointing stage and maturity stage, respectively, compared with SCK treatment; the enzymatic activity of SKC treatment increased by $11.6 \%, 12.5 \%$ and $2.5 \%$, respectively; the enzymatic activity of SDY treatment increased by $19.3 \%, 6.9 \%$ and $14.8 \%$, respectively; and the enzymatic activity of SFH treatment increased by $19.3 \%, 6.9 \%$ and $14.8 \%$, respectively. They increased by $10.0 \%$, $2.9 \%$ and $18.9 \%$, respectively.

S-SC activity of Salicornia salina in seedling and jointing stage was lower than that in spraying mode, but there was no significant difference at maturity stage. During the growth period of Salicornia salsa, the fertilization methods were different, and the activity of Salicornia salicornis was different among different fertilization treatments. The activity of S-SC in seedling stage, jointing stage and ripening stage of Salicornia salsa under different fertilization methods were SJDF $>\mathrm{SDY}>\mathrm{SKC}>\mathrm{SFH}>\mathrm{SCK}$, $\mathrm{SJDF}>\mathrm{SKC}>\mathrm{SDY}>\mathrm{SFH}>\mathrm{SCK}, \mathrm{SJDF}>\mathrm{SFH}>\mathrm{SDY}>\mathrm{SCK}>\mathrm{SKC}$, while the activity of S-SC in seedling stage, jointing stage and ripening stage was 
$\mathrm{TJDF}=\mathrm{TDY}=\mathrm{TFH}=\mathrm{TKC}=\mathrm{TCK}$,

$\mathrm{TJDF}=\mathrm{TDY}=\mathrm{TKC}=\mathrm{TFH}=\mathrm{TCK}$

and

$\mathrm{TJDF}=\mathrm{TDY}=\mathrm{TFH}=\mathrm{TKC}=\mathrm{TCK}$, respectively. Therefore, hole fertilization can promote the comprehensive utilization rate of fertilizer, benefit the absorption and utilization of nutrients by halophytes, and improve soil enzyme activity.

\section{Effects of spraying-based fertilization on S-CAT activity}

Figure 6 depicts the effect of spraying fertilization on S-CAT activity under Mulched fertilization.

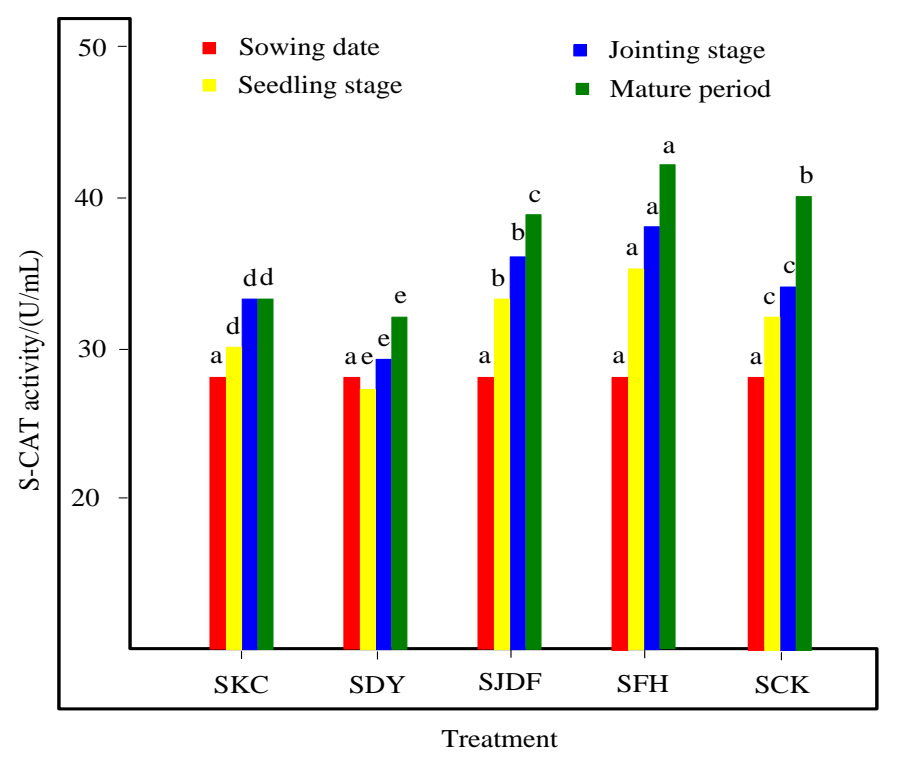

Figure 6. Effects of spraying-based fertilization on S-CAT activity

Figure 6 showed that the activity of S-CAT reached its peak at the ripening stage of Salicornia salsa under the spraying mode, and the activity of SFH treatment was the highest. Compared with SCK, the activity of SFH treatment increased by $9.5 \%, 10.5 \%$ and $4.0 \%$ at seedling stage, jointing stage and mature stage, respectively. The effect of other fertilization treatments on S-CAT activity was not obvious.

S-CAT activity was higher in seedling stage and jointing stage of Salicornia salsa than in spraying mode, but lower in ripening stage than in spraying mode. During the growth period of Salicornia salsa, there were some differences in S-CAT activity among different fertilization treatments. The activity of S-CAT at seedling stage, jointing stage and maturity stage of Salicornia salsa under different fertilization methods were SFH > $\mathrm{SJDF}>\mathrm{SCK}>\mathrm{SKC}>\mathrm{SDY}, \mathrm{SFH}>\mathrm{SJDF}>\mathrm{SCK}>\mathrm{SKC}>\mathrm{SDY}, \mathrm{SFH}>\mathrm{SCK}>$ SJDF $>$ SKC > SDY, and the activity of S-CAT at seedling stage, jointing stage and maturity stage of Salicornia salicornis were TFH $>$ TCK $>$ TJDF $>$ TKC $>$ TDY, $\mathrm{TFH}>\mathrm{TCK}>\mathrm{TJDF}>\mathrm{TKC}>\mathrm{TDY}$ and $\mathrm{TFH}>\mathrm{TCK}>\mathrm{TJDF}>\mathrm{TKC}>\mathrm{TDY}$. Therefore, hole fertilization can promote the utilization of fertilizer, benefit the absorption and utilization of nutrients by halophytes, and improve soil enzyme activity. 


\section{Effects of spraying-based fertilization on $S$-UE activity}

Figure 7 depicts the effect of spraying fertilization on S-UE activity under Mulched fertilization.

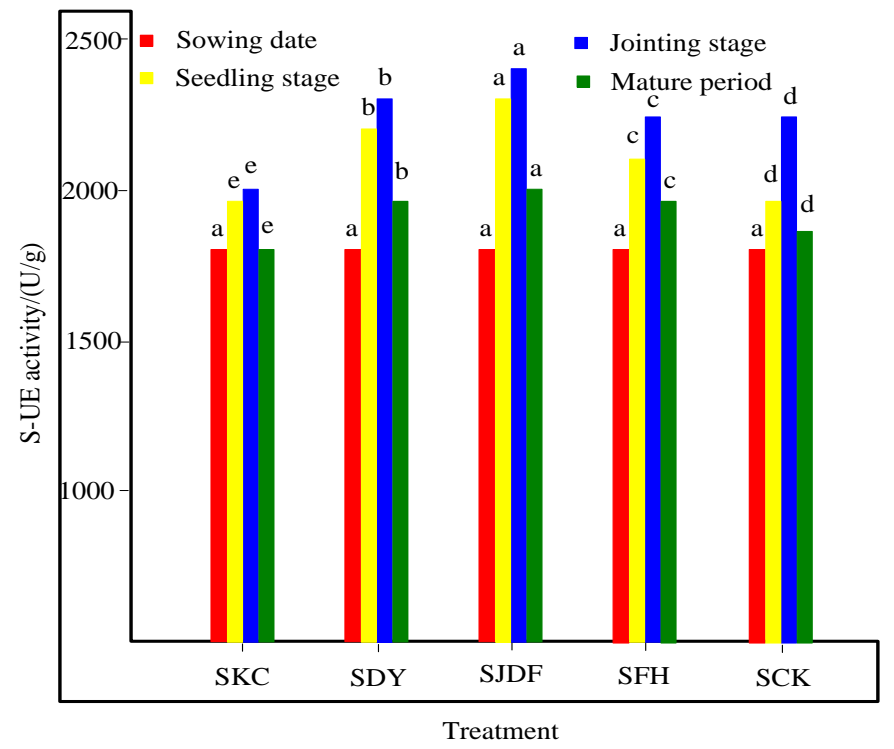

Figure 7. Effects of spraying-based fertilization on S-UE activity

Figure 7 shows that the peak value of S-UE activity occurs at elongation stage of Salicornia salsa under spraying mode. SJDF treatment has the greatest effect on S-UE activity. Compared with SCK, the activity of S-UE in SJDF treatment increased by $14.4 \%, 4.6 \%$ and $8.6 \%$ at seedling, elongation and maturity stages, respectively; SDY treatment increased by $12.0 \%$ and $2.0 \%$, respectively; SFH treatment increased by $4.3 \%$, $0.4 \%$ and $6.3 \%$, respectively. The effect of SKC on S-UE activity was not obvious.

S-UE activity of Salicornia salsa was higher than that of Salicornia salicornis in the growth period. The activity of S-UE in the seedling stage, jointing stage and mature stage of Salicornia salicornis was JDF $>$ SDY > SFH > SCK > SKC. Therefore, hole fertilization can promote the utilization of fertilizer, benefit the absorption and utilization of nutrients by halophytes, and improve soil enzyme activity.

\section{Discussions}

In this paper, the correlation between long-term different fertilization methods and soil enzyme activities in rhizosphere of halophytes was studied. The effects of different fertilization methods and different fertilization treatments on S-SC, S-CAT and S-UE enzymes in root soil during the development of Salicornia salicornis were studied. The results show that:

The activities of S-SC, S-CAT and S-UE could be promoted by mulching and fertilization at any time. Among them, film mulching combined with fertilization had the best effect, and the three enzymes activities of soil were the highest. This is because the saline soil is hot and dry in summer, and the temperature is high. Film mulching improves soil moisture and temperature, which is conducive to the absorption and 
transformation of soil nutrients, thereby improving soil enzyme activity. The soil enzyme activities of plastic film mulching and fertilization treatments also increased, but the effects of the two treatments were different, which was due to the large fluctuation of temperature in the saline soil area in summer morning and evening. The soil enzyme activity was also affected by different fertilization time, and the soil enzyme activity was the highest when the soil enzyme was sampled on July 1.

The activities of S-SC and S-UE increased first and then decreased with time during the growth period of Salicornia salsa, and reached the highest level at jointing stage. During this period, Salicornia salicornis grew vigorously, its root system developed, and its nutrient demand increased, which stimulated the activities of S-SC and S-UE to increase rapidly to meet the growth needs of Salicornia salicornis. It was soil microbial activity. S-CAT activity gradually increased during the growth period of Salicornia salsa and reached its peak at maturity. Because of the maturity of Salicornia salicornis, the residue and litter of Salicornia salicornis increased in rhizosphere, which induced its activity to increase to oxidize and decompose hydrogen peroxide in soil.

From the effect of different fertilization treatments on soil enzyme activity, it can be seen that the combination of chemical fertilizer and starch-dissolving microbial fertilizer has the greatest influence on S-SC activity and S-UE activity, and the combination of chemical fertilizer and microbial fertilizer of compound bacteria has the greatest influence on S-CAT activity. The results showed that the combined application of chemical fertilizer and starch-dissolving microbial fertilizer could significantly enhance the activity of S-SC and S-UE, and the combined application of chemical fertilizer and microbial compound fertilizer could significantly enhance the activity of S-CAT, because the input of microbial fertilizer and inorganic fertilizer not only provided abundant energy for the soil, but also brought a large number of microorganisms into the soil, thus stimulated the energy metabolism of the soil. It can greatly improve soil enzyme activity. This is consistent with the research results of relevant scholars, so the combination of chemical fertilizer and microbial fertilizer can improve soil environment and soil enzyme activity.

The S-SC activity in the seedling stage and jointing stage of Salicornia salsa was lower than that in the spraying treatment, and the law of maturity was not obvious. This indicated that spraying fertilizer was beneficial to the early absorption of Salicornia salicornis root system, so the S-SC activity was higher in the seedling stage and jointing stage. The activity of S-CAT in the seedling and jointing stage was higher than that in the spraying treatment, and in the mature stage was lower than that in the spraying treatment. This indicated that the hole application was beneficial to reduce the toxic effect of hydrogen peroxide on Salicornia salicornis, which might be caused by root exudates, soil physical and chemical properties, soil environment and crop growth in different growth stages of Salicornia salicornis. As a result, S-UE activity was lower in spraying treatment than in hole application treatment during the growth period of Salicornia salsa, so hole application of chemical fertilizer could improve the effective utilization rate of nitrogen and promote the absorption and utilization of fertilizer by Salicornia salicornis. This may be due to the effects of Fertilization on soil nutrients, mineral elements, root metabolism and secretion activities. In order to reveal the effect of long-term different fertilization methods on the enzyme activity of halophyte rhizosphere soil, the halophyte was used as the research object to carry out the root bag culture on the coastal saline soil. The effects of mulching, non-mulching and no fertilization on the activities of invertase, catalase and urease in rhizosphere soil were 
studied, and the effects of mulching and no fertilization on the activities of invertase in rhizosphere soil were also studied. Catalase and urease in rhizosphere soil of saline alkali soil were studied. Bacillus, Bacillus licheniformis, Bacillus amylolyticus and compound microbial fertilizer all affected the enzyme activities of the three soils. The results showed that mulching could promote the activities of S-SC, S-CAT and S-UE, and the effect of mulching and fertilization was the best at any time. The changes of soil enzyme activity were the same in the growth period. The activities of invertase and urease were the highest in jointing stage and catalase was the highest in mature stage. In conclusion, the application of plastic film mulching combined with fertilization, inorganic fertilizer and microbial fertilizer can improve soil enzyme activity, soil fertility and sustainable productivity.

\section{Conclusions}

In this paper, the relationship between long-term fertilization and soil enzyme activity in rhizosphere of halophytes was studied. A typical halophyte, Salicornia salina, was taken as the research object to study the soil enzyme activity in rhizosphere during the growth period of Salicornia salicornis under different fertilization methods and fertilization treatments. The results showed that the activities of S-SC, S-CAT and S-UE could be promoted by mulching and fertilization, and the effect of mulching combined with fertilization was the best. Different soil enzymatic activities showed different changes during the growth period of Salicornia salina. Soil invertase and soil urease activities showed a trend of increasing first and then decreasing, and soil catalase activity showed a trend of increasing gradually. There are some differences in soil invertase, catalase and urease activities under different fertilization treatments. The long-term application of organic fertilizer and chemical fertilizer can improve the content of soil organic matter, nitrogen and phosphorus nutrients, and enhance the activities of soil invertase, protease, pulse enzyme, phosphatase and catalase. In a certain control period, the transformation of soil available nitrogen and phosphorus is related to growth and development stage, soil enzyme activity and fertilization mode. Single application of chemical fertilizer is not conducive to the improvement of soil organic matter and nitrogen and phosphorus nutrients, and the enzyme activity of soil is also low. The relationship between fuel, feed and fertilizer in rural areas is quite contradictory. Crop straw is mainly used for fuel, feed and paper making. In fact, the residue in the soil every season is only crop stubble. Therefore, the long-term application of livestock manure and green manure in the medium and low yield soil is conducive to the increase of soil organic matter content and the enhancement of soil biological activity, and creates a good soil biochemical environment for the stable and high yield of crops.

Therefore, hole fertilization can improve the comprehensive utilization rate of fertilizer, promote the transformation and release of nutrients in soil, and benefit the growth and development of halophytes. Different fertilization treatments showed that microbial fertilizer combined with chemical fertilizer could improve soil environment, enhance soil enzyme activity, and provide favorable growth conditions for halophytes. Therefore, under the combination of plastic film mulching and fertilization, hole fertilization is the main treatment. Adding microbial fertilizer can improve soil enzyme activity, physical and chemical properties, and promote soil fertility level and sustainable production capacity. In the future research, we can study how to reduce the 
transformation and release time of soil nutrients, and provide strong experimental data and theoretical reference for the research of soil enzyme activity.

Acknowledgements. National natural science foundation of China - Effects of different water and nitrogen treatments on soil microflora in wheat fields and their regulatory mechanisms (No. 51509085); Fund project for high-level talents of Henan University of Science and Technology: Study on the spatial distribution regulation mechanism of nitrogen compensation utilization in maize and soybean intercropping (No. 2015010).

\section{REFERENCES}

[1] Chen, J. F., Sun, H., Xia, Y., Cai, K. X., Liu, H. Y., Li, Y. Y., Guo, R. L., Hou, B., Feng, S., Jiang, X. X. (2017): Changes in Soil Enzyme Activity and Nutrient Content in Different Years of Continuous Cropping Tobacco Fields. - Asian Agricultural Research 9(5): 100-104.

[2] Chen, S., Zhu, Z. K., Yuan, H. Z. (2018): Dynamics of Rice Photosynthesized Carbon Input and Its Response to Nitrogen Fertilization at the Jointing Stage:13 C-CO2 Pulselabeling. - Environmental Science 39(1): 331.

[3] Cheng, M., Peng, W., Kopittke, P. M. (2016): Cadmium accumulation is enhanced by ammonium compared to nitrate in two hyperaccumulators, without affecting speciation. Journal of Experimental Botany 67(17): 5041-5050.

[4] Cunha, J. C., Ruiz, H. A., Silva, J. D. G. (2017): Phytoextraction Potential of Atriplex Nummularia Plants under Nitrogen and Phosphate Fertilization. - Communications in Soil Science \& Plant Analysis 48(1): 20-36.

[5] Duan, P. P., Liu, L. (2019): Target Aspect Angle Estimation of SAR Images Based on Correlation Analysis. - Journal of China Academy of Electronics and Information Technology 14(1): 46-50.

[6] Fan, P., Chen, D., He, Y. (2016): Alleviating salt stress in tomato seedlings using Arthrobacter and Bacillus megaterium isolated from the rhizosphere of wild plants grown on saline-alkaline lands. - Int J Phytoremediation 18(11): 1113-1121.

[7] Gong, Z., Bao, G. Z., Li, Y. F. (2017): Physiological Response of Ryegrass Seedlings under Freezing-Thawing and Combined with NaHCO3 Stress. - Journal of Jilin University (Science Edition) 55(2): 451-457.

[8] Gschwendtner, S., Engel, M., Lueders, T. (2016): Nitrogen fertilization affects bacteria utilizing plant-derived carbon in the rhizosphere of beech seedlings. - Plant \& Soil 407(12): 203-215.

[9] Gu, M. Y., Tang, G. M., Liu, H. L. (2016): Effects of cotton stalk biochar on microbial community structure and function of continuous cropping cotton rhizosphere soil in Xinjiang, China. - Ying Yong Sheng Tai Xue Bao 27(1): 173-181.

[10] Hicks Pries, C. E., Castanha, C., Porras, R. C., Torn, M. S. (2017): The whole-soil carbon flux in response to warming. - Science 355(6332): 1420.

[11] Li, H., Hu, J., Xu, K. (2017): Effect of storage period and enzyme activity on bioelectrical property of potato battery. - Chinese Journal of Power Sources 41(7): 1001-1003.

[12] Liu, H., Ruwan, D. U., Zhao, J. (2016): Effects of fertilization on enzyme activities and bacterial community structures in rhizosphere soil of flue-cured tobacco. - Tobacco Science \& Technology 49(11): 1-6.

[13] Ma, Q., Ran, L., Hu, B. R. (2016): Temperature Dependency Characteristic of SiC MOSFET Static Performance Based on Comparative Analysis with Si IGBT. - Journal of Power Supply 14(6): 67-79. 
[14] Nawaz, M. F., Bourrie, G., Gul, S. (2016): Exploring the dynamics of physico-chemical properties of soil waters in the rhizosphere of rice plants. - Pakistan Journal of Agricultural Sciences 51(2): 351-361.

[15] Poeplau, C., Bolinder, M. A., Kirchmann, H. (2016): Phosphorus fertilisation under nitrogen limitation can deplete soil carbon stocks - evidence from Swedish metareplicated long-term field experiments. - Biogeosciences 13(19): 16527-16551.

[16] Song, W. L., Yu, Y., Wang, Z. (2018): Study on Temperature Field Uniformity Control in Micro Carbon Plant Cultivation System. - Computer Simulation 35(2): 205-210.

[17] Tang, X., Placella, S. A., Daydé, F. (2016): Phosphorus availability and microbial community in the rhizosphere of intercropped cereal and legume along a P-fertilizer gradient. - Plant \& Soil 407(1-2): 119-134.

[18] Van Veen, B. K., Rutten, W. L. C., Wallinga, W. (2017): The Influence Of The Position Of The Active Fiber Relative To The Muscle Boundary In Computing Single Fiber Action Potentials. - Acta Biol Colomb 18(3): 449-464.

[19] Wang, T., Ma, Y. D., Xu, Y. D., Guo, S. J., Wang, W. Y., Han, X. H., Yang, G. H., Wang, X. J. (2018): Relationship between soil nutrients and enzyme activity in Robinia pseudoacacia plantation. - Chinese Journal of Ecology 37(7): 2083-2091.

[20] Xu, L., Yi, M., Yi, H. (2017): Manure and mineral fertilization change enzyme activity and bacterial community in millet rhizosphere soils. - World Journal of Microbiology \& Biotechnology 34(1): 8.

[21] Zhao, S., Zhou, N., Zhao, Z. (2016): Estimation of endophytic bacterial diversity in root of halophytes in Northern Xinjiang by high throughput sequencing. - Acta Microbiologica Sinica 56(10): 1583-1594.

[22] Zhou, B., Lin, X. (2016): Design of wireless water-saving irrigation system for urban vegetation. - Automation \& Instrumentation 4: 134-135. 